\title{
Reply to the Letter-to-the-editor written by J. J. Bevelacqua and S. M. J. Mortazavi on: "Radon survey in the kindergartens of three Visegrad countries (Hungary, Poland and Slovakia)" (DOI 10.1007/s10967-018-6374-3)
}

\author{
Monika Müllerová ${ }^{1}$ · Jadwiga Mazur ${ }^{2}$ - Anita Csordás ${ }^{3} \cdot K_{a}$ arol Holý ${ }^{1}$ - Dominik Grządziel ${ }^{2}$ - Tibor Kovács ${ }^{3}$. \\ Krzysztof Kozak ${ }^{2} \cdot$ Iveta Smetanová ${ }^{4} \cdot$ Karolina Danyłec $^{2} \cdot$ Patrícia Kureková $^{1} \cdot$ Erika Nagy $^{3} \cdot$ Matej Neznal $^{5}$
}

Published online: 8 April 2019

๑) Akadémiai Kiadó, Budapest, Hungary 2019

\section{Dear Editor-in-Chief,}

Radiation protection is based on a conservative approach, which is still valid in Visegrad countries. It means that the motivation for radon monitoring in the kindergartens was based on a valid radiation protection for inhabitants. The aim of our paper was not to compare models describing the relation dose-effect.

It is still not clear and is still being discussed which of the models is correct for low doses. The idea that low doses are not harmful is controversial and there are papers confirming both approaches. The extensive research (lasting for decades) should be made to confirm credibly the effect of low doses. Investigations indicate that also LNT model probably should have a threshold, but in the radiation protection LNT model is still valid and used.

This is Reply from Author to Letter to the Editor for the https:// doi.org/10.1007/s10967-019-06488-8.

Monika Múllerová

mullerova@fmph.uniba.sk

1 Department of Nuclear Physics and Biophysics, Faculty of Mathematics, Physics and Informatics, Comenius University, Mlynská dolina F1, Bratislava 4842 48, Slovak Republic

2 Laboratory of Radiometric Expertise, Institute of Nuclear Physics PAN, Radzikowskiego 152, 31-342 Kraków, Poland

3 Social Organisation for Radioecological Cleanliness, Egyetem str 10, Veszprem 8200, Hungary

4 Division of Geophysics, Earth Science Institute, Slovak Academy of Sciences, Dúbravská cesta 9, P.O.Box 106, Bratislava 840 05, Slovak Republic

5 RADON, v.o.s., Novákových 6, Prague 8180 00,

Czech Republic
The main goal of the article was to study the radon levels in kindergartens in V4 countries in a view of the Directive (No. 2013/59/EURATOM). The authors did not intend to discuss the strengths and weaknesses of LNT and hormesis hypotheses. Another reason why LNT model was mentioned is that in EU countries the radon action plan was approved and member countries incorporated it in their legislation and lowered their reference levels for indoor radon from 400 to $300 \mathrm{~Bq} \mathrm{~m}^{-3}$.

Publisher's Note Springer Nature remains neutral with regard to jurisdictional claims in published maps and institutional affiliations. 